\title{
탄소나 $\mathrm{TiO}_{2}$ 를 포함한 다양한 흡착제의 휘발성 유기물 흡착에 대한 연구
}

\section{김영독*}

성균관대학교 화학과, 수원 440-746

(2012년 1월 10일 받음, 2012년 3월 2일 수정, 2012년 3월 12일 확정)

\begin{abstract}
본 연구에서는 톨루엔 등의 휘발성 유기물의 흡착량을 정성, 정량적으로 연구할 수 있는 새로운 장비를 구축하였으며, 이를 이용하여 기존의 탄소를 기반으로 하는 다양한 흡착제와 원자층 증착으로 만든 $\mathrm{TiO}_{2}$ 박막구조의 톨루엔 흡착에 대한 연구를 진행하였다. $\mathrm{TiO}_{2}$ 박막구조의 흡착제가 기존의 탄소기반 흡착제보다 톨루엔 흡착량이 뛰어난 것을 입증하였으며, 이는 원자층 증착으로 제조한 $\mathrm{TiO}_{2}$ 박막 표면의 높은 농도의 $\mathrm{OH}$ 그룹의 높은 톨루엔 친화력과 연관성이 있는 것으로 나타났다. 또한 본 장비를 이용하여 가역적인 흡착과 비가역적인 흡착을 구분할 수 있음을 보여주었다.
\end{abstract}

주제어 : 흡착, 휘발성 유기화합물, 탄소, 이산화티타늄

\section{I. 서 론}

불균일 촉매의 연구에서 표면적 내지 표면의 흡착자 리를 정확히 구하는 연구는 중요한 역할을 한다. 다양한 불균일 촉매들의 촉매 활성을 비교할 경우, 모든 촉매들 의 흡착자리의 수를 맞춘 상태에서 반응성의 상이함을 연구하는 것이 현실적으로 매우 어렵기 때문에, 대부분 불균일 촉매활성을 정량화시킬 때에는 촉매활성을 흡착 자리의 수 내지는 표면적으로 Turn-Over Number (TON)라는 것을 일상적으로 사용하게 되며, 정확히 TON를 알아내기 위해서는 표면적 내지는 흡착자리 수 를 정확히 정량화시키는 것이 중요하다 [1].

표면적을 측정하는 데 가장 많이 사용되는 법은 질소의 흡착등온식을 토대로 한 BET법이다 [2]. 대부분 액체 질소 온도에서 특정한 질소의 분압에서 질소의 흡착량을 측정하 고, 이 데이터를 토대로 표면적을 알아내는 방법이다. 질소 이외에도 다른 분자의 흡착을 이용하여 표면적 내지는 흡 착자리수를 알아내는 방법이 있다. 이외에도 전자현미경으 로 촉매의 모양을 연구하여 표면적을 유추해내는 방법을 사용하는 연구들도 있기는 하지만 그 정확도가 매우 떨어 지는 것으로 알려져 있다 [3].

본 연구에서는 새로운 방식의 기체 흡착 연구 장치를 디
자인하여 상온에서 다양한 기체의 고체표면위의 흡착에 대 한 연구를 하도록 하였으며, 이에 대해서 간단히 소개하고 자 한다. 특히 이 연구 장치는 특정한 온도에서 표면에 가 역적으로 흡착되어 있는 흡착종과 비가역적으로 흡착되어 있는 흡착종을 정량적으로 분류해 내는 데 유용하다. 인체 에 해롭기 때문에 공기중에서 효율적으로 제거하는 것이 중요한 이슈가 되고 있는 휘발성 유기물들 중 톨루엔의 다 양한 고체표면의 흡착에 대해서 어떠한 연구가 이 장치를 이용하여 가능한지 소개하도록 하겠다.

\section{II. 실험 방법}

\section{1. 실험 장치}

먼저 실험장치는 크게 기체와 고체 시료가 들어가는 반응 기와 반응기 안의 기체의 조성을 분석하는 분석실 두 부분 으로 구성되어 있으며 모든 장비는 스테인레스 스틸로 만들 어져 있다. 먼저 반응기는 다시 시료가 들어가 있는 부분 (A)과 비어 있는 두 부분 (B)으로 구성되어 있으며, 두 부분 의 사이에는 gate valve가 자리 잡고 있다. 이 gate valve 가 열려 있는 상태에서 $\mathrm{A}, \mathrm{B}$ 두 부분을 로터리 펌프와 터보

*[전자우편] ydkim91@skku.edu 
펌프를 이용하여 $1 \times 10^{-8}$ torr까지 압력을 낮출 수 있으며, 이후 gate valve를 닫고 $\mathrm{A}$ 에 reference gas $\left(\mathrm{Ar}\right.$ 이나 $\mathrm{N}_{2}$ )와 톨루엔 가스를 주입한다. 이때 각각의 기체의 분압은 Superbee gauge를 이용하여 측정할 수 있다. 이후에 gate valve를 열면 $\mathrm{A}$ 에 차 있던 기체가 고체시료에 노출되게 된 다. reference gas는 고체 표면에 전혀 흡착하지 않는 기체

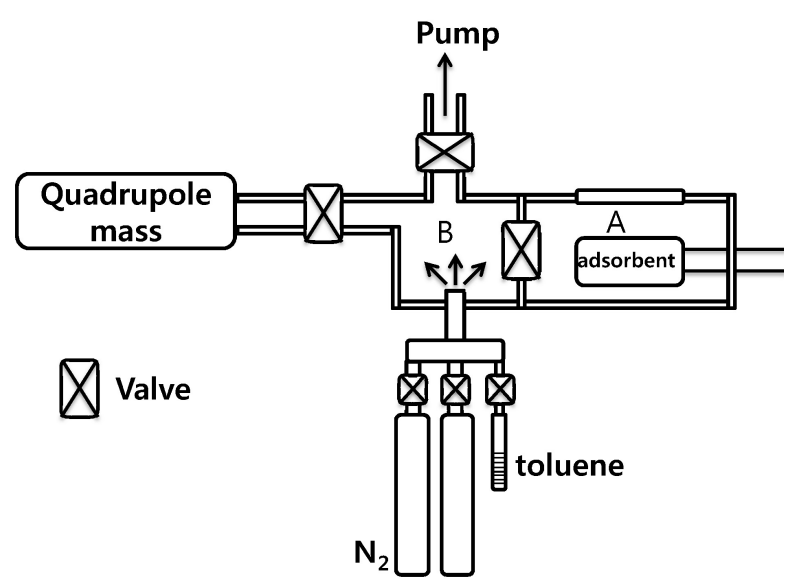

Figure 1. Schematic description of the experimental set-up used for the adsorption behavior studies in the present work.
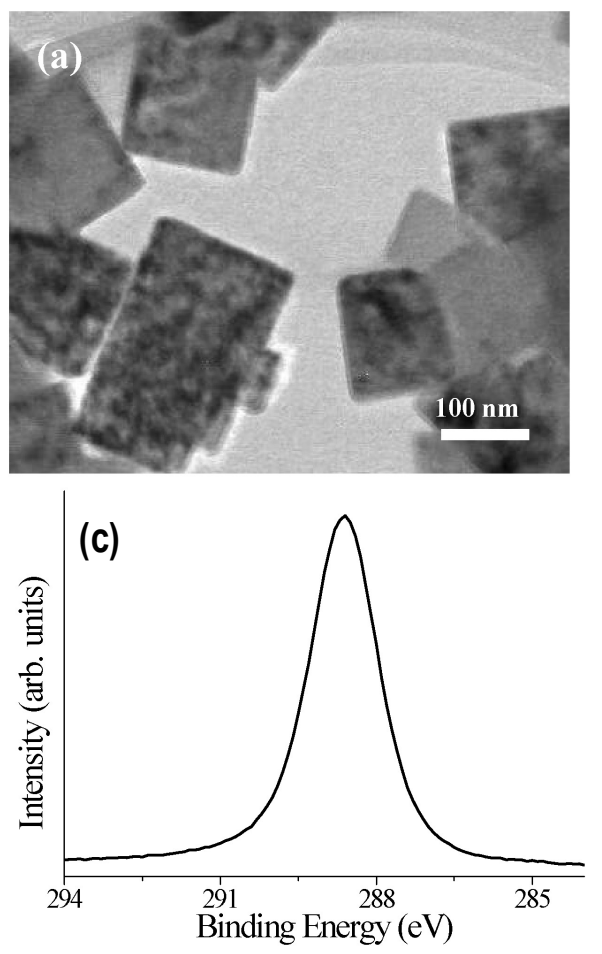

를 사용하여야 하며, 상온실험에서는 $\mathrm{N}_{2}$ 나 $\mathrm{Ar}$ 을 사용할 수 있다. gate valve를 연 후 시간이 지나면서 $\mathrm{N}_{2}$ 의 분압에 대 한 톨루엔 기체의 상대적인 부분 압력이 감소하게 되며, 감 소된 톨루엔 부분압력은 표면에 흡착되는 톨루엔의 양에 해 당하게 된다. 모든 실험에서 $\mathrm{N}_{2}$ 를 reference 기체로 사용하 였으며, $\mathrm{N}_{2}$ 의 초기 부분압력은 $3 \mathrm{torr}$, 톨루엔의 초기 부분 압력은 1 torr였고, 시료의 온도는 상온이었다.

Reference gas에 대한 톨루엔의 부분 압력의 감소의 측정 은 분석실에서 이루어진다. 고진공조건의 분석실에는 사극자 질량분석기가 있으며, 분석실과 반응기사이에는 leak valve가 있어 반응기의 기체들의 상대적인 부분압력의 변화를 반응기 의 기체 중 아주 미량을 분석실로 흘려서 분석할 수 있게 된다.

\section{2. 시료}

본 연구에서는 기존에 흡착제로 잘 알려져 있는 다양한 탄소 나노구조들을 톨루엔의 흡착제로 이용하였다. 활성탄 섬유(한국 탄소 공업사에서 구입), 다중벽 탄소나노튜브(한 화 나노텍에서 구입, $\mathrm{CM}-100)$, 나노다이아몬드(microdiamant에서 구입, $0 \sim 0.1 \mathrm{micron})$ 등의 구조를 사용하였
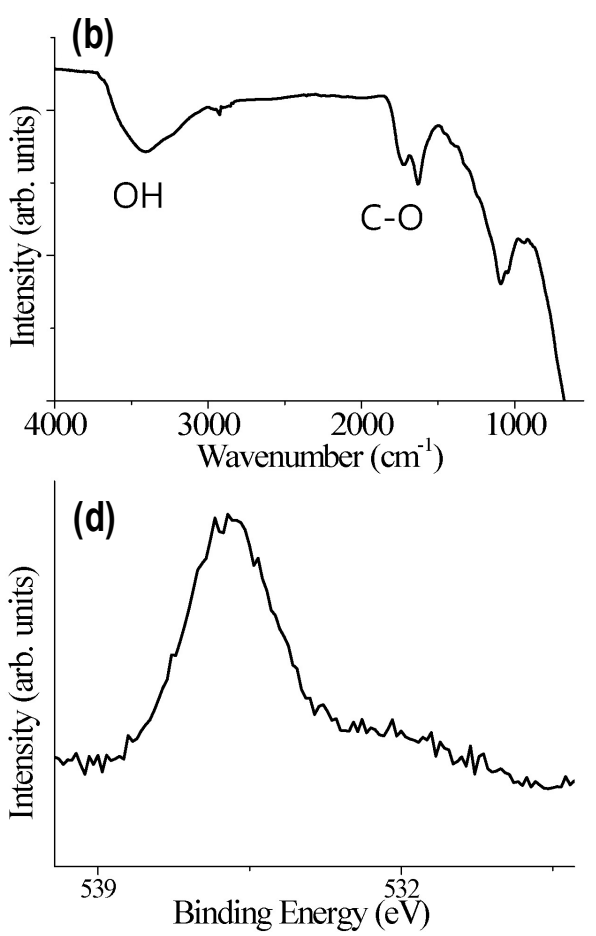

Figure 2. Results of the characteriztion of nanodiamond (a) Transmission electron microscopy image (b) FT-IR data (c) C 1s core level spectrum (d) $\mathrm{O}$ 1s core level spectrum. 
다. 탄소 나노튜브와 나노다이아몬드의 경우에는 실험을 용이하게 하기 위하여 pellet의 형태로 시료를 만들어서 흡 착 실험에 사용하였다. 이외에도 크기가 100 150 nm정도 인 나노다이아몬드 분말위에 $\mathrm{TiO}_{2}$ 가 원자층 증착법으로 증 착된 형태의 산화물 흡착제도 사용하였다. 원자층 증착을 위해서는 TTIP (Aldrich 구입, 순도 $97 \%$ )와 $\mathrm{H}_{2} \mathrm{O}$ 를 전구 체로 사용하였으며 증착온도는 $150{ }^{\circ} \mathrm{C}$ 였다.

Fig. 2와 3에는 본 실험에 사용된 다중벽 탄소나노튜브 와 나노다이아몬드의 분석 결과들이 소개되어 있다. 나노 다이아몬드(Fig. 2)의 경우 탄소가 $\mathrm{sp}^{3}$ 혼성화 궤도함수를 가지고 있기 때문에, 순수한 다이아몬드 표면에는 배위가

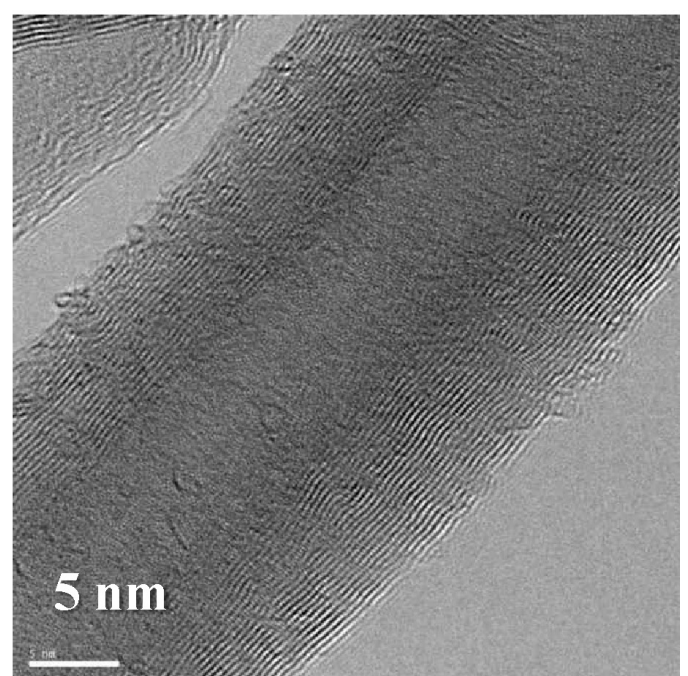

Figure 3. Transmission electron microscopy image of multiwalled carbon nanotube.

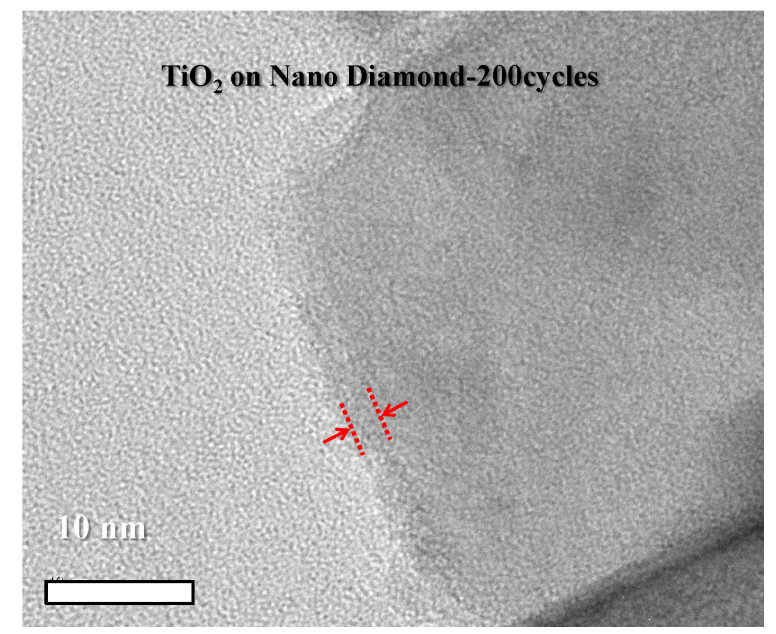

Figure 4. Transmission electron microscopy image of $\mathrm{TiO}_{2}$ covered nanodiamond.
포화되지 않은 많은 탄소원자들이 자리잡고 있어야 한다. FT-IR 데이터와 X-선 광전자 분광법 데이터 (특히 O 1s) 에서 볼 수 있듯이 나노다이아몬드 표면에는 많은 산소를 함유하고 있는 작용기 $(\mathrm{C}-\mathrm{OH}, \mathrm{C}=\mathrm{O})$ 들이 존재하여 배위 적으로 포화되지 않은 탄소들의 배위를 포화시키고 있음을 알 수 있다. Fig. 3, 4에는 다중벽 탄소나노튜브와 $\mathrm{TiO}_{2}$ 가 증착된 나노다이아몬드의 전자현미경 사진이 나와 있는데, 특히 Fig. 4 에서 두께가 $2 \mathrm{~nm}$ 정도가 되는 $\mathrm{TiO}_{2}$ 박막이 나 노다이아몬드 표면위에 증착되어있음을 알 수 있다. 이 $\mathrm{TiO}_{2}$ 박막은 상대적으로 저온 $\left(150{ }^{\circ} \mathrm{C}\right)$ 에서 증착되었기 때 문에 X-선 회절에서 아무런 $\mathrm{TiO}_{2}$ 상을 찾을 수 없는 비정질 이며, $500{ }^{\circ} \mathrm{C}$ 열처리 이후에만 아나타제 상이 나타나게 된 다. $\mathrm{TiO}_{2}$ 의 원자층 증착에 대한 자세한 내용은 참고문헌에 자세히 소개되어 있다 $[4,5]$.

실험에 사용된 reference기체는 $\mathrm{N}_{2}$ 이며, 톨루엔, 증류 수 등이 흡착 실험을 위하여 사용되었다. 증류수, 톨루엔 등은 모두 액체질소 온도로 얼리고 나머지 기체를 뽑아내 고 녹이는 과정을 반복하여 정제하였으며, leak valve를 이용하여 톨루엔, 증류수 증기를 반응기 안에 주입하였다. Reference gas 역시 leak valve를 이용하여 정확한 양을 반응기에 주입할 수 있었다.

\section{III. 결과 및 고찰}

Fig. 5 는 분석실에서 얻은 반응시간에 따른 reference 기

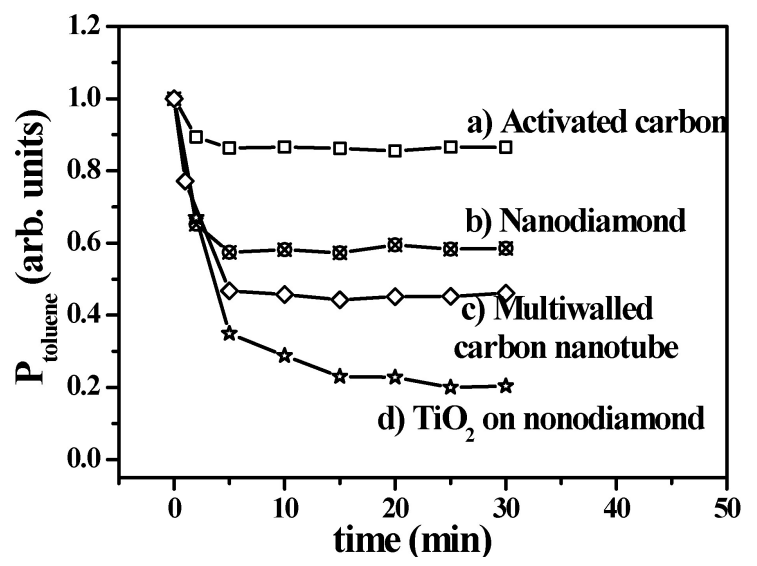

Figure 5. Adsorption of toluene on various adsorbents. Types of samples used for each experiment is given in the figure. 

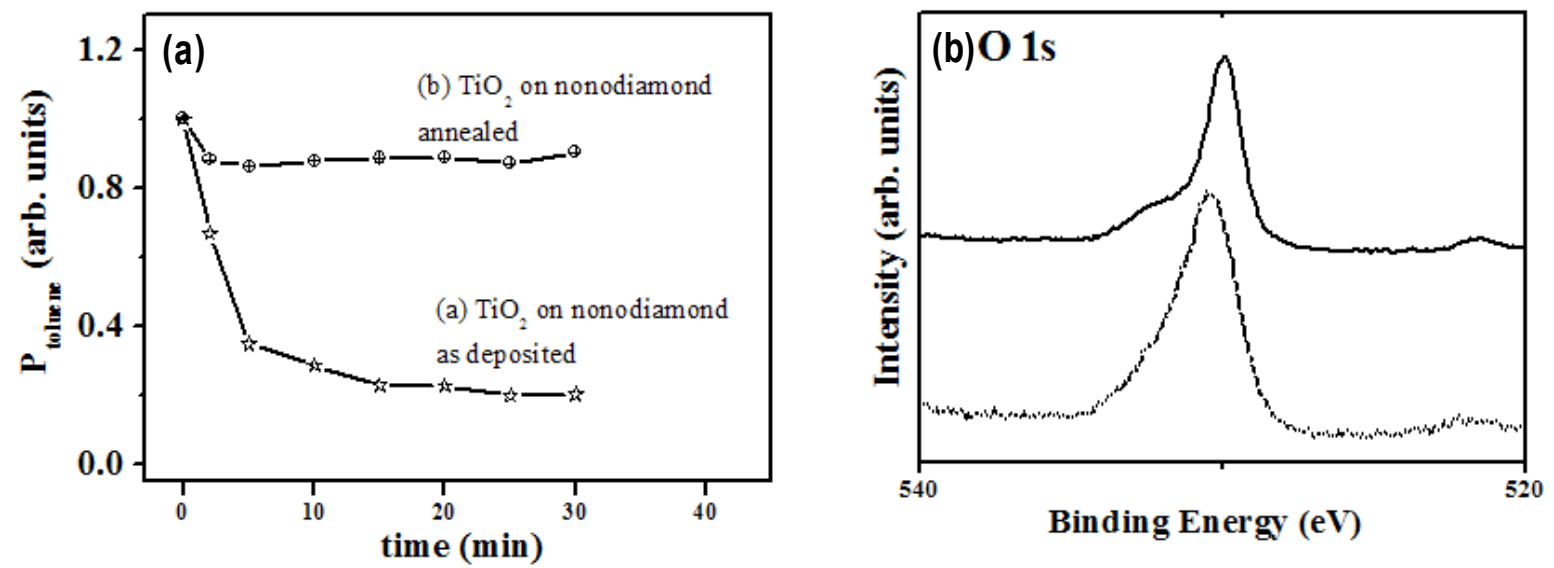

Figure 6. (a) Toluene adsorption on as-prepared and $500{ }^{\circ} \mathrm{C}$-annealed $\mathrm{TiO}_{2} /$ nanodiamond (b) $\mathrm{O}$ 1s spectrua of the $\mathrm{TiO}_{2}$ /nanodiamond sample before and after heat treatment at $500{ }^{\circ} \mathrm{C}$. The shoulder at $533 \mathrm{eV}$ corresponds to the $\mathrm{OH}$ groups.

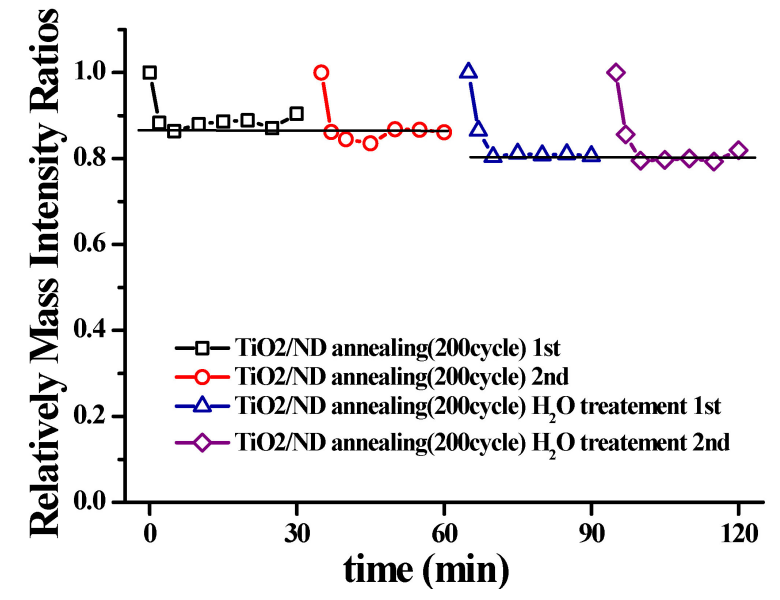

Figure 7. Results of repeated experiments of toluene adsorption on $\mathrm{TiO}_{2}$ /nanodiamond. After second experiment, the sample was exposed to water vapor. Then, the chamber was evacuated and further adsorption experiments of toluene were carried our.

체에 대한 톨루엔 기체의 감소량을 도식한 것으로 활성탄, 다중벽 탄소 나노튜브, 나노다이아몬드, $\mathrm{TiO}_{2}$ 가 증착된 나 노다이아몬드를 흡착제로 사용하였다. Gate valve를 열기 전 (반응전) 질소의 부분 압력은 3 torr였으며, 톨루엔의 부 분 압력은 1 torr 였다. Gate valve를 열고 기체가 시료표면 에 노출되면서 톨루엔의 표면흡착에 의한 상대적인 부분 압 력의 감소가 일어난다. 시료가 들어 있지 않은 경우 (blank 실험)에서는 전혀 톨루엔의 상대적 분압의 변화가 없는 것으 로 나타났기 때문에, 톨루엔의 상대적 분압 변화는 모두 탄 소 소재 표면위에 흡착된 결과에 기인한 것으로 볼 수 있다.

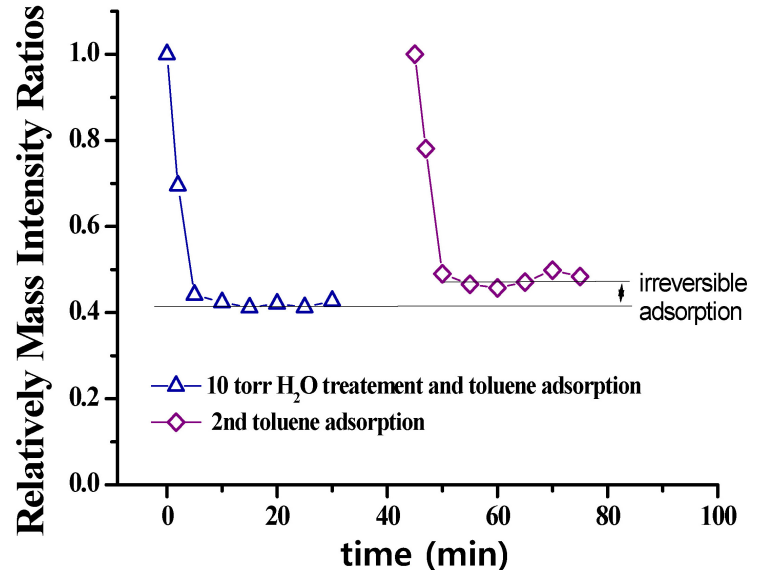

Figure 8. $\mathrm{TiO}_{2} / \mathrm{NiO}$ compsite structure was used for toluene adsorption experiment. For the preparation of this sample, $150-$ cycles of ALD for $\mathrm{TiO}_{2}$ deposition on $10-\mathrm{nm}$ sized $\mathrm{NiO}$ particles was used. For further description of the sample preparation, please refer to Ref. 7.

Fig. 5에 사용된 각 시료의 표면적은 $2.3 \mathrm{~m}^{2}$ 로 동일하다. 각 시료의 BET 비표면적을 측정하였으며, 실험에 사용된 시료 의 질량을 조절하여 시료당 전체 표면적을 일정하게 맞출 수 있었다. 단위 표면적당 톨루엔의 흡착량을 고려했을 때, 기 존의 휘발성 유기물의 흡착제로 가장 널리 알려져 있는 활성 탄보다 다중벽 탄소나노튜브와 나노다이아몬드의 흡착력이 오히려 뛰어나다는 것을 알 수가 있다. 특이한 것은 본 실험 실에서 합성한 $\mathrm{TiO}_{2}$ 가 증착된 나노다이아몬드가 가장 높은 톨루엔 흡착 활성을 보인다는 것이다.

본 연구에서는 톨루엔의 부분압력과 반응기의 부피를 정 확하게 계산할 수 있기 때문에, 이결과를 Fig. 5 의 데이터 
와 함께 이용하여 흡착제가 단위 면적당 몇 개의 톨루엔 분 자를 흡착하는지를 이상기체 방정식의 범위 안에서 계산해 낼 수 있다. 예를 들어서 $\mathrm{TiO}_{2}$ 가 증착된 나노다이아몬드의 경우 대략적으로 $1 \mathrm{~nm}^{2}$ 당 6 개의 톨루엔 분자를 흡착할 수 있는 것으로 계산되었다.

일반적으로 $\mathrm{TiO}_{2}$ 표면이 강한 톨루엔 흡착이 친화력을 갖는다는 것이 알려진 바 없고 Daegussa P-25 TiO 2 같은 경우에도 톨루엔 흡착을 상온에서 전혀 일으키지 않기 때 문에 [6], 본 실험실에서 합성한 $\mathrm{TiO}_{2}$ 박막의 톨루엔 흡착 에 대한 높은 친화력은 기존의 $\mathrm{TiO}_{2}$ 와는 다른 독특한 표면 구조에 기인한 것으로 볼 수 있다. 본 실험실에서 합성한 $\mathrm{TiO}_{2}$ 박막의 높은 톨루엔의 친화력의 원인을 찾기 위한 추 가적인 실험을 실시하였으며 Fig. 6에 그 결과가 소개되어 있다. $150{ }^{\circ} \mathrm{C}$ 에서 증착된 $\mathrm{TiO}_{2}$ 박막은 높은 톨루엔의 친화 력을 가지나, 이 시료를 $500{ }^{\circ} \mathrm{C}$ 에서 열처리하면 톨루엔 흡 착량이 현저히 감소된다. 이는 여러 가지 요인으로 설명가 능하나, 톨루엔 흡착에 높은 친화력을 보이는 표면에 있는 $\mathrm{OH}$ 그룹들이 열처리를 통하여 감소하게 되면서 톨루엔 흡 착량이 줄어들게 된다고 설명할 수 있다. $\mathrm{X}$-선 광전자 분 광법 $\mathrm{O} 1 \mathrm{~s}$ 데이터의 $533 \mathrm{eV}$ 의 봉우리는 $\mathrm{OH}$ 그룹에 기인하 며 열처리 후 이 봉우리의 세기가 감소함을 Fig.6에서 볼 수 있다.

위의 가설을 증명하기 위한 추가적인 실험을 실행하였으 며, 그 결과가 Fig. 7에 나타나 있다. 열처리한 $\mathrm{TiO}_{2} /$ 나노다 이아몬드 박막을 다시 수증기에 노출시킨 후에 수증기를 반 응기에서 제거하고 톨루엔을 흡착시켰을 때 톨루엔의 흡착 량이 다시 증가하였다. 즉 수증기에 의해 표면에 생성된 $\mathrm{OH}$ 그룹이 톨루엔 흡착력을 높였다는 것이다. 여기서 한 가지 언급할 점은 Daegussa의 P-25 TiO 2 경우에도 물처리에 의 해서 표면에 $\mathrm{OH}$ 기의 농도를 높였을 경우, 톨루엔 흡착력이 증가하였다는 것이다 [7]. 물론 박막은 비정질이며 Daegu$\mathrm{ssa}$ 의 P-25 $\mathrm{TiO}_{2}$ 는 아나타제와 루타일의 혼합으로 구성되 어 있어 본 실험에서 얻은 박막시료와의 직접적인 비교는 어렵지만 $\mathrm{OH}$ 기가 톨루엔의 흡착력을 증가시킨다는 [7]번 참고문헌의 결과는 본 실험의 결과와 일치한다.

또 한 가지 언급해야 할 점은 이 흡착실험을 반복했을 때, 즉 흡착 이후 다시 반응기안의 기체를 뽑아내고, 진공 상태를 만든 뒤 다시 기체를 주입할 때, 첫 번째 실험과 똑 같은 양의 톨루엔 흡착이 이루어지는 것을 Fig. 7에서 확인 할 수 있다는 것이다. 이는 지금까지 본 연구에서 소개한
모든 톨루엔 흡착은 상온에서 가역적인 톨루엔 흡착에 해 당함을 의미한다. 가역적인 흡착이라 함은 톨루엔 증기가 존재할 때에는 톨루엔 증기와 흡착된 톨루엔 분자사이의 평형상태에 도달하지만, 증기가 제거되면 흡착된 분자도 모두 탈착되는 것이다. 반대로 상온에서 비가역적인 톨루 엔의 흡착이 일어나는 경우라면 첫 번째 실험에 이어 반복 되는 두 번째 흡착실험에서는 이미 모든 흡착자리가 차 있 기 때문에 더 이상 흡착이 일어나지 않아야 한다. 본 연구 실에서, 테스트한 일부 시료(수증기 처리한 $\mathrm{TiO}_{2} / \mathrm{NiO}$ 혼합 물)의 경우 이러한 현상이 일부 발견되었다(Fig. 8) [8]. 즉 첫 번째 흡착실험에서 나타난 흡착량보다 두 번째 반복실 험에서 나타난 톨루엔 흡착량이 적었는데, 그 흡착량의 차 이가 첫 번째 실험에서 비가역적으로 흡착된 툴루엔 양에 해당된다.

\section{$\mathrm{IV}$. 결 론}

본 연구에서 새롭게 디자인 한 흡착 측정 장비를 이용하 여 다양한 흡착제의 톨루엔 흡착을 연구하였다. 기존의 탄 소기반 흡착제보다 본 실험실에서 합성한 $\mathrm{TiO}_{2}$ 박막이 톨루 엔 흡착능력이 더 뛰어남을 확인하였다. 또한 본 실험에서 는 가역흡착과 비가역흡착을 정량적으로 구분해 낼 수 있 는 가능성이 있음을 보여주었다.

\section{감사의 글}

This research was supported by a grant from the Fundamental R\&D Program for Core Technology of Materials funded by the Ministry of Knowledge Economy, Republic of Korea.

\section{참 고 문 헌}

[1] M. Valden, X. Lai, and D. W. Goodman, Science 281, 1647 (1998).

[2] H. -K. Jin, J. -M. Lee, and S. -K. Ryu, J. Korean Vacuum Soc. 2, 491 (1993). 
[3] M. E. Grass, Y. W. Zhang, D. R. Butcher, J. Y. Park, Y. M. Li, H. Bluhm, K. M. Bratlie, T. F. Zhang, and G. A. Somorjai, Angw. Chem. Int. Ed. 47, 8893 (2008).

[4] H. J. Lee, H. O. Seo, D. W. Kim, K. -D. Kim, Y. Luo, D. C. Lim, H. Ju, J. W. Kim, J. Lee, and Y. D. Kim, Chem. Comm. 47, 5605 (2011).

[5] B. H. Lee and M. M. Sung, J. Korean Vacuum Soc. 19, 91 (2010).
[6] H. O Seo, K. -D. Kim, Y. Luo, M. J. Kim, N. K. Dey, and Y. D. Kim, Bull. Kor. Chem. Soc. 31, 2333 (2010).

[7] Y. Luo, W. S. Tai, H. O. Seo, K. -D. Kim, M. J. Kim, N. K. Dey, Y. D. Kim, K. H. Choi, and D. C. Lim, Catal. Lett. 138, 76 (2010).

[8] K. -D. Kim, J. W. Nam, H. O. Seo, Y. D. Kim, and D. C. Lim, J. Phys. Chem. C. 115, 22954 (2011). 


\title{
Investigations of Adsorption Behaviors of Various \\ Adsorbents Including Carbon, or $\mathrm{TiO}_{2}$
}

\author{
Young Dok Kim* \\ Department of Chemistry, Sungkyunkwan University, Suwon 440-746 \\ (Received January 10, 2012, Revised March 2, 2012, Accepted March 12, 2012)
}

New equipment for quantitative and qualitative adsorption of volatile organic compound was set up, and using this equipment, adsorption behaviors of various carbob-based nanomaterials and $\mathrm{TiO}_{2}$ thin films prepared by atomic layer deposition were compared. We could conclud that $\mathrm{TiO}_{2}$ thin films can show higher adsorption capacity of toluene comparing to the carbon-based nanostructures due to higher affinity of the surface $\mathrm{OH}$ groups of $\mathrm{TiO}_{2}$ towards toluene adsorption. We also demonstrate that our method allows to discriminate reversible and irreversible adsorptions at a given temperature.

Keywords : Adsorption, Volatile organic compounds, Carbon, $\mathrm{TiO}_{2}$

*[E-mail] ydkim91@skku.edu 